\title{
Entrar na língua alemã pela porta do léxico: recursos para a aprendizagem autónoma de vocabulário
}

\section{Judite Carecho}

Univ. de Coimbra/FLUC - DLLC e CELGA-ILTEC, Coimbra, Portugal judite@fl.uc.pt

Rute Soares

Univ. de Coimbra/FLUC - DLLC e CELGA-ILTEC, Coimbra, Portugal rute.soares@fl.uc.pt

\begin{abstract}
Resumo
Após breve apresentação do projeto Aprendizagem Autónoma do Alemão através do Léxico (ALEX), que disponibiliza aos alunos recursos para aprendizagem de vocabulário de forma flexível e autónoma, incluindo exercícios interativos, são descritos os resultados da fase-piloto do projeto, que decorreu na FLUC em 2017-18. Reflete-se sobre aspetos que podem ter contribuído para que a participação dos alunos ficasse aquém do esperado, sendo um desses aspetos objeto de particular atenção. Trata-se das listas de palavras que o projeto também disponibiliza e que servem de base às restantes atividades. Dadas as dificuldades enfrentadas no processo de seleção deste vocabulário e a necessidade de comparar o resultado com outras listas de vocabulário básico do alemão, equacionam-se várias opções para a escolha de uma lista a usar numa comparação sistemática. Feita a escolha, é sumariamente apresentado o resultado da comparação efetuada e, por fim, elencam-se propostas de alteração resultantes da reflexão realizada, no sentido de obter melhores resultados em próximas edições do projeto.
\end{abstract}

Palavras-chave: aprendizagem da língua estrangeira, vocabulário, língua alemã, listas de vocabulário, vocabulário básico

\section{Abstract}

Our text starts with a brief presentation of the project Learning German Autonomously with Vocabulary, which provides vocabulary learning resources (including interactive 
CARECHO, Judite; Soares, Rute - Entrar na língua alemã pela porta do léxico: recursos para a aprendizagem autónoma de vocabulário

Para lá da tarefa: implicar os estudantes na aprendizagem de línguas estrangeiras no ensino superior. Porto: FLUP, 2019, pp. 95-115 DOI: https://doi.org/10.21747/9789898969217/paraa5

exercises) that students can use in an autonomous and flexible way. During the pilot phase of the project, which took place at FLUC in 2017-18, student participation failed to meet our expectations. Reflections are offered about various factors that could have led to those results, special attention being paid to one aspect: the word lists that are available as a learning resource, but also form the basis of all other learning activities offered. Due to the problems posed by the selection of vocabulary for those lists and the need to compare them with other basic vocabulary lists, several options are considered for a systematic comparison. The result of the comparison with the selected list is then presented and conclusions are drawn regarding possible amendments to the project, so as to achieve better results in student participation and learning.

Keywords: foreign language learning, vocabulary, German language, vocabulary lists, basic vocabulary

\section{1 - Introdução: o projeto ALEX e o seu contexto}

A aprendizagem de vocabulário é uma das componentes mais complexas do processo de aprender uma língua estrangeira, tanto numa dimensão quantitativa, devido ao número potencialmente ilimitado de palavras que é necessário aprender, como numa dimensão qualitativa, pois saber uma palavra implica não só ser capaz de identificar e reproduzir a sua forma escrita, assim como a sua forma sonora, mas também conhecer o seu significado e os seus padrões combinatórios (cf. Laufer \& Nation, 2012, p. 163).

Este processo complexo estende-se necessariamente no tempo, pois implica várias fases: como refere Ma (2017, pp. 46-47), a aprendizagem das palavras implica que o aprendente atente na forma da palavra, identifique o seu significado e ligue este significado à forma através de algum tipo de atividade, devendo esta ligação ser subsequentemente consolidada à medida que o aprendente realiza outras atividades que envolvam a palavra, quer reconhecendo-a em textos orais ou escritos, quer usandoa na sua própria produção discursiva.

Foi a consciência da complexidade da aprendizagem do vocabulário e da sua importância na aprendizagem da língua - para ultrapassar obstáculos na compreensão e facilitar a expressão na língua estrangeira - que nos levou a criar o projeto Aprendizagem Autónoma do Alemão através do Léxico (ALEX). Na fase-piloto, que decorreu no ano letivo de 2017-18, foram disponibilizados às turmas de Alemão da Licenciatura em Línguas Modernas da FLUC recursos para aprendizagem do 
CARECHO, Judite; Soares, Rute - Entrar na língua alemã pela porta do léxico: recursos para a aprendizagem autónoma de vocabulário

Para lá da tarefa: implicar os estudantes na aprendizagem de línguas estrangeiras no ensino superior. Porto: FLUP, 2019, pp. 95-115 DOI: https://doi.org/10.21747/9789898969217/paraa5

vocabulário com que os alunos contactavam nas aulas. Entre esses recursos encontram-se documentos com listas de palavras que foram selecionadas a partir das listas para aprendizagem contidas no manual usado nas aulas de língua. Nas listas, as palavras são, se possível, agrupadas por áreas temáticas e encontram-se sempre associadas a uma frase de contextualização e a uma tradução adequada a esse contexto. A tradução constitui um recurso para favorecer associações corretas entre a forma da palavra e o seu significado em contexto - tirando partido de se tratar de grupos de alunos que partilham a mesma língua materna - e pode ser usada para ultrapassar as primeiras barreiras na compreensão de uma língua com que, em geral, os alunos não contactam regularmente fora das aulas.

As listas de palavras encontram-se no blogue www.projetoalex.pt, onde existe também um tutorial sobre diferentes estratégias para aprendizagem de vocabulário, assim como instruções para usar as diferentes ferramentas tecnológicas associadas ao projeto, com as quais os alunos podem realizar inúmeras atividades interativas. As aplicações usadas no âmbito do projeto são o treinador de vocabulário do dicionário Leo (www.leo.org) e os suportes para a criação de exercícios interativos Quizlet (https://quizlet.com) e Learning Apps (https://learningapps.org/), cuja utilização no âmbito deste projeto é descrita e exemplificada em Carecho, Soares e Fernandes (2018, p. 81-83). Trata-se de atividades propostas para uso flexível e autónomo por parte dos alunos, fora das aulas, no computador ou no telemóvel, o que permite tirar proveito da omnipresença deste aparelho no quotidiano dos alunos e também da natureza multimodal dos conteúdos digitais, associando à forma escrita das palavras, para além da tradução, a sua forma sonora e ainda imagens ilustrativas. Os exercícios propostos podem envolver a associação de alguns destes elementos, ou a escrita, e têm como objetivo consolidar a aprendizagem do léxico que consta das listas do projeto, indo ao encontro do que defendem autores como Ma (2017, p. 51) quanto ao papel de exercícios interativos na aprendizagem de vocabulário.

No ano em que decorreu a fase-piloto do projeto, as turmas de Alemão da licenciatura em Línguas Modernas da FLUC, distribuídas por três níveis, contavam com quase 150 alunos inscritos, dos quais 93 responderam ao questionário inicial do projeto: 
CARECHO, Judite; Soares, Rute - Entrar na língua alemã pela porta do léxico: recursos para a aprendizagem autónoma de vocabulário Para lá da tarefa: implicar os estudantes na aprendizagem de línguas estrangeiras no ensino superior. Porto: FLUP, 2019, pp. 95-115 DOI: https://doi.org/10.21747/9789898969217/paraa5

\begin{tabular}{lcc} 
& $\begin{array}{c}\text { Número de alunos } \\
\text { inscritos }\end{array}$ & \multicolumn{2}{c}{$\begin{array}{c}\text { Número de respostas ao } 1 . \\
\text { questionário do projeto ALEX }\end{array}$} \\
1. ano & 70 & 45 \\
$2 .^{\circ}$ ano & 48 & 27 \\
$3 . \circ$ ano & 29 & 21 \\
TOTAL & 147 & 93
\end{tabular}

Figura 1. Turmas de Alemão da licenciatura em Línguas Modernas (2017-18)

De acordo com os resultados dos inquéritos, com que se pretendia caracterizar o público-alvo do projeto, ${ }^{1}$ trata-se de um grupo de alunos relativamente heterogéneo no que respeita ao seu percurso académico e aos conhecimentos que já tinham da língua alemã antes de integrarem estas turmas. Usam muito frequentemente dispositivos tecnológicos, com destaque para o telemóvel, e, quando questionados sobre os seus hábitos relativamente aos métodos de estudo de vocabulário, dão as respostas apresentadas no seguinte gráfico:

${ }^{1}$ Outros dados destes inquéritos estão disponíveis em Soares, Carecho e Fernandes (no prelo). 
CARECHO, Judite; Soares, Rute - Entrar na língua alemã pela porta do léxico: recursos para a aprendizagem autónoma de vocabulário

Para lá da tarefa: implicar os estudantes na aprendizagem de línguas estrangeiras no ensino superior. Porto: FLUP, 2019, pp. 95-115 DOI: https://doi.org/10.21747/9789898969217/paraa5

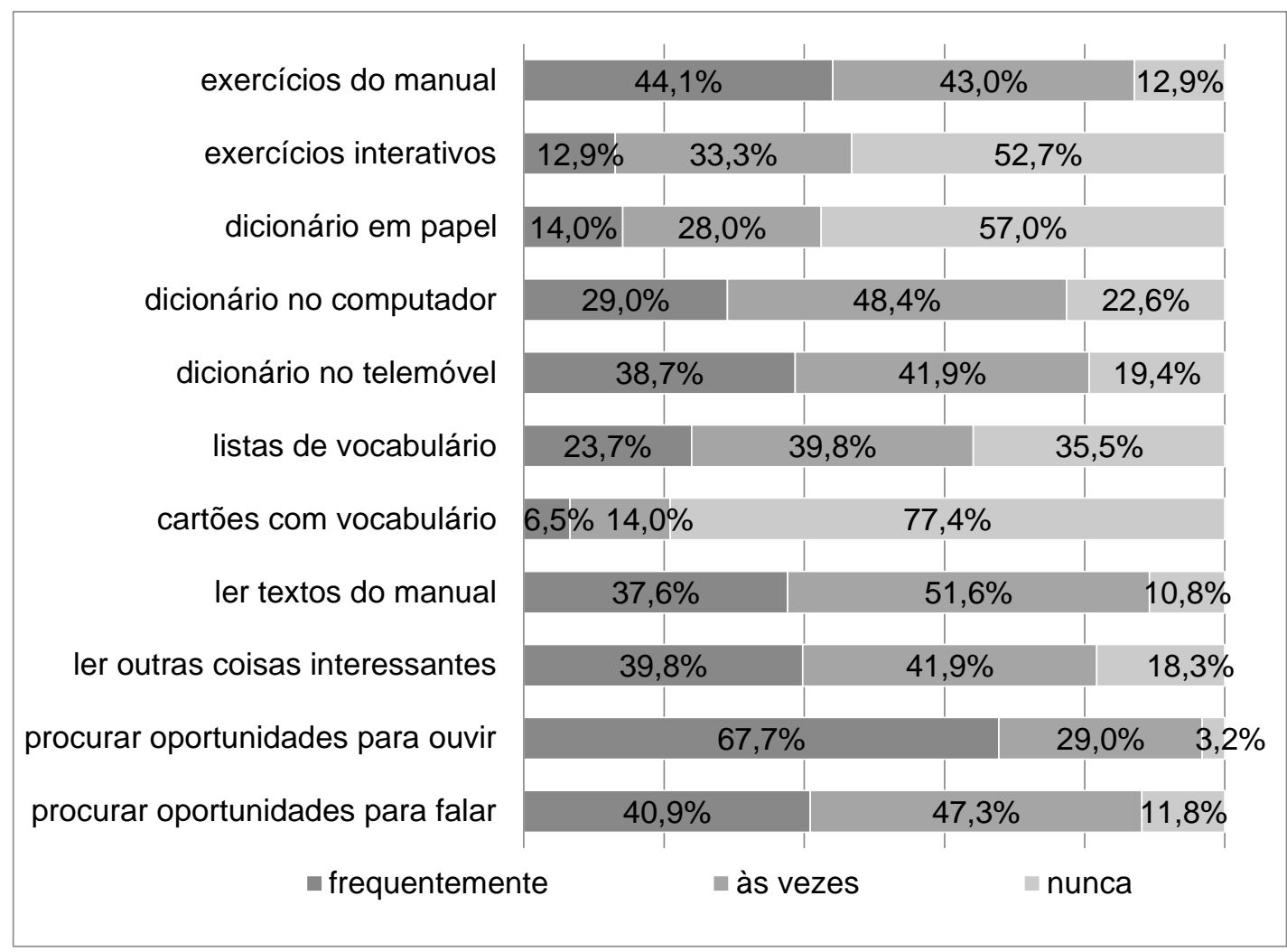

Figura 2. Resposta à pergunta sobre métodos de estudo de vocabulário habituais

O método de estudo que se revela mais popular é procurar situações para ouvir falar a língua estrangeira, possivelmente em filmes, séries e música, sendo plausível que este método seja popular por ser mais informal e menos semelhante ao trabalho em aula. Seguem-se métodos como fazer exercícios no manual, ler textos e procurar oportunidades para falar, assim como usar o dicionário no telemóvel. As estratégias que são propostas no projeto - o uso de listas e de cartões, bem como os exercícios interativos - só raramente são utilizadas pelos alunos. O desafio do projeto seria, pois, alterar esta realidade.

\section{2 - Resultados da fase-piloto}

Quer nas sessões de apresentação do projeto, quer nos inquéritos de avaliação dos recursos, a que os alunos responderam após alguns meses, registámos algumas reações de grande entusiasmo, como a afirmação por parte de alunos de $2 . .9$ e $3 . .9$ ano de que teria sido bom que o projeto existisse quando entraram para 01. ano, ou 0 desejo de que fosse dada continuidade à disponibilização de novos exercícios e listas à 
CARECHO, Judite; Soares, Rute - Entrar na língua alemã pela porta do léxico: recursos para a aprendizagem autónoma de vocabulário

Para lá da tarefa: implicar os estudantes na aprendizagem de línguas estrangeiras no ensino superior. Porto: FLUP, 2019, pp. 95-115 DOI: https://doi.org/10.21747/9789898969217/paraa5

medida que os alunos fossem aprendendo vocabulário temático específico nas aulas, por acharem o projeto muito útil. No entanto, no geral, a frequência de utilização prática dos recursos ficou aquém das expectativas: de acordo com os inquéritos de avaliação, contámos 44 registos de uso dos recursos do projeto num universo de 147 alunos, 93 dos quais tinham respondido aos primeiros inquéritos. Como seria de esperar, entre todos os materiais e métodos de aprendizagem de vocabulário que o projeto disponibiliza, as aplicações parecem ser os recursos mais usados pelos alunos, com $77 \%$ desses registos de uso. Entre as aplicações, o Quizlet parece ser a mais popular, com $36 \%$ dos registos, seguida do Leo com 25\% e do Learning Apps com 16\%. As listas de vocabulário, disponibilizadas no blogue, são responsáveis por $16 \%$ do total dos registos de uso, sendo os restantes $7 \%$ referentes ao estudo com materiais em papel, que é sugerido no tutorial sobre aprendizagem de vocabulário.

Se analisarmos os registos de uso das aplicações do projeto do ponto de vista da sua frequência, confirma-se o baixo nível de utilização dos recursos, como se verifica na tabela seguinte:

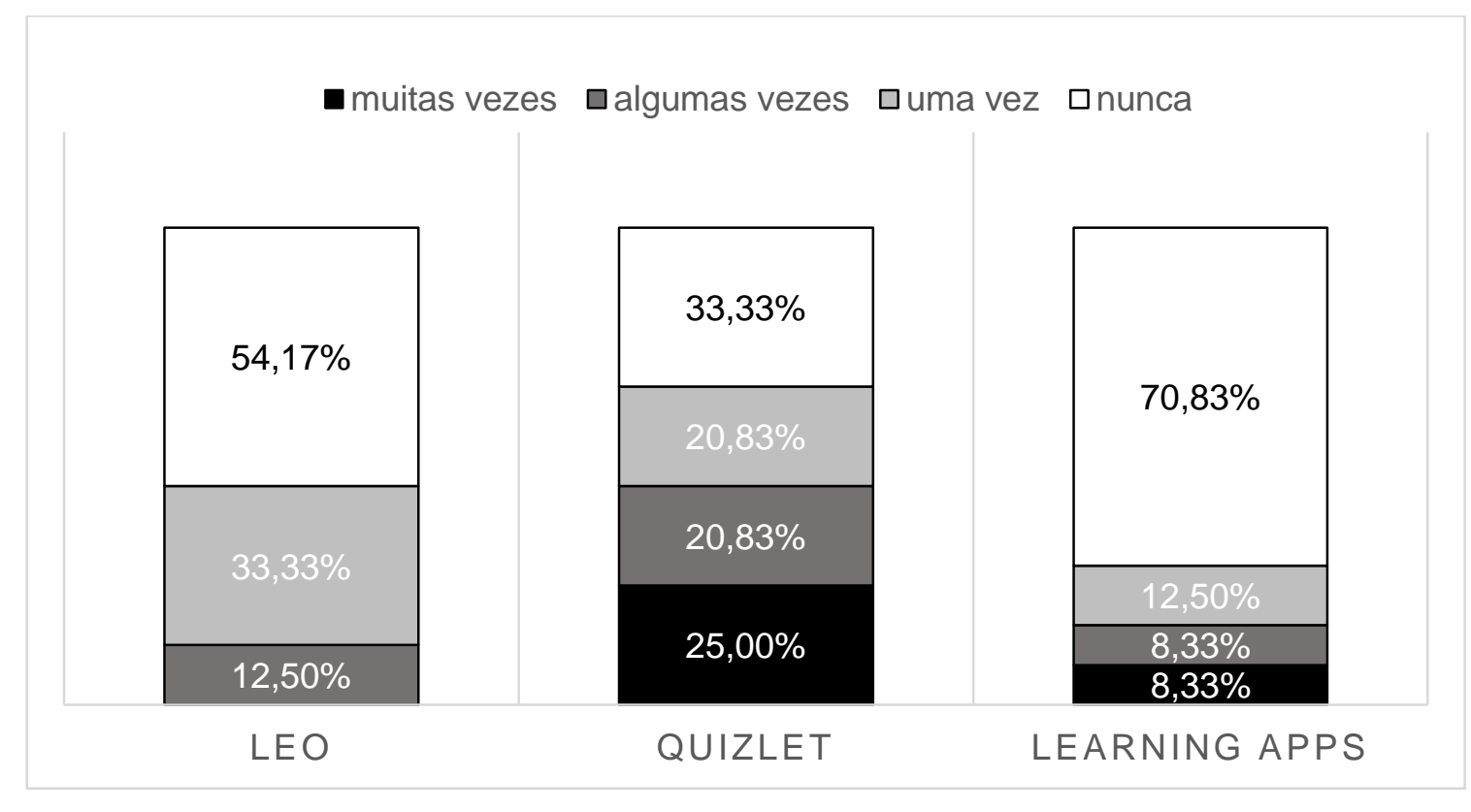

Figura 3. Índice de frequência de uso das aplicações

O uso frequente é minoritário e muitos dos registos referem-se a utilizações únicas, de alunos que experimentaram os recursos uma só vez. No entanto, confirma-se que a aplicação mais popular é o Quizlet, aquela que é mais facilmente usada no telemóvel, o que pode indiciar uma preferência por este dispositivo. 
CARECHO, Judite; Soares, Rute - Entrar na língua alemã pela porta do léxico: recursos para a aprendizagem autónoma de vocabulário

Para lá da tarefa: implicar os estudantes na aprendizagem de línguas estrangeiras no ensino superior. Porto: FLUP, 2019, pp. 95-115 DOI: https://doi.org/10.21747/9789898969217/paraa5

Relativamente à distribuição temporal do uso dos recursos, sobressai a noção de que são usados de forma mais intensiva antes de testes e exames para tentar colmatar falhas, muitas vezes por alunos que estão a enfrentar dificuldades. Por outro lado, há alunos com muito bom desempenho que já tinham outros métodos eficazes para o estudo de vocabulário e preferem continuar a usá-los.

\section{3 - Reflexão sobre os resultados}

Embora não se possa dizer que sejam positivos, os resultados não são totalmente inesperados, face à descrição de outros projetos de trabalho autónomo de alunos com recursos tecnológicos, onde também é visível a discrepância entre as suas reações e atitudes positivas face aos projetos apresentados e a falta de participação na utilização prática dos recursos disponíveis:

(...) learners have often expressed positive attitudes towards using mobile devices for educational purposes, but this has not been translated directly into high levels of engagement to the tools that are provided to them (...) learners of French in Norway indicated that they believed a mobile blog was a good idea but ultimately very few learners actually used it. (Stockwell, 2016, p. 951)

Este tipo de reação dos alunos é diferente do que existe em experiências com recursos tecnológicos usados na aula ou em ambiente controlado, onde a recetividade é maior do que em trabalho autónomo, daí que se defenda que "(...) there is a need to look deeper into the reasons why learners have not always embraced unsupervised mobile learning as enthusiastically as expected" (Stockwell, 2016, p. 953).

Foi nesse sentido que procurámos inventariar possíveis razões para a falta de participação dos alunos, olhando para o que poderá ter corrido menos bem nas diferentes dimensões do projeto.

Relativamente a questões de organização do projeto, os resultados menos positivos poderão estar ligados a falhas na divulgação inicial junto dos alunos (realizada por email) e também a atrasos na disponibilização de uma parte dos recursos, motivada pela exiguidade da equipa responsável pela sua criação. As sessões presenciais de apresentação do projeto aos alunos realizadas numa segunda fase revelaram-se úteis, sobretudo as que tiveram uma componente prática de treino, o que vai ao encontro da necessidade de formação dos alunos para o trabalho autónomo que é defendida, por exemplo, em Hubbard (2013). Relativamente à conceção dos exercícios interativos, é 
CARECHO, Judite; Soares, Rute - Entrar na língua alemã pela porta do léxico: recursos para a aprendizagem autónoma de vocabulário

Para lá da tarefa: implicar os estudantes na aprendizagem de línguas estrangeiras no ensino superior. Porto: FLUP, 2019, pp. 95-115 DOI: https://doi.org/10.21747/9789898969217/paraa5

possível que alguns deles sejam demasiado grandes para um padrão de mobile learning que pretende aproveitar pequenas pausas ou deslocações entre atividades do quotidiano (cf. Zhang, 2015, p. 17 e Stockwell, 2016, p. 954). Por outro lado, o facto de parte das aplicações, nomeadamente o Leo e também o Learning Apps, serem mais adequadas ao computador do que ao telemóvel pode ter constituído uma desvantagem, dada a preferência que os alunos parecem demonstrar pelo uso do telemóvel. Esta suposição é corroborada pelo facto de, nas observações dos inquéritos de avaliação dos recursos, haver pedidos de "versão para telemóvel".

Refletindo agora sobre a perspetiva dos alunos, nas sessões de divulgação com prática detetámos dificuldades técnicas inesperadas no contacto com as aplicações, parcialmente devidas ao facto de a tradução portuguesa das instruções do treinador de vocabulário Leo estar incompleta; as dificuldades observadas podem ter constituído um obstáculo à utilização dos recursos. Um outro aspeto que nos parece ter pesado é o facto de o projeto ter sido apresentado como trabalho autónomo e voluntário sem uma recompensa direta nas aulas, o que pode ser um fator de desencorajamento para alunos que não têm hábitos de trabalho autónomo sem ligação imediata à avaliação. A um nível mais geral, outra circunstância desfavorável pode ter sido a atitude dos alunos relativamente ao estudo do vocabulário, que tende a ser uma componente negligenciada em detrimento da gramática. Indícios deste problema são pedidos de exercícios de gramática nos inquéritos de avaliação, como resposta à nossa solicitação de sugestões de melhoria para o ALEX, bem como a procura autónoma de exercícios de gramática nas aplicações associadas ao ALEX.

Para além de todos estes fatores que podem ter contribuído para a reduzida participação dos alunos, a nossa reflexão estendeu-se também àquilo que é a própria essência do projeto, as palavras com que trabalhámos, e que sempre tivemos alguma dificuldade em selecionar a partir das extensas listas de palavras do manual. É a esse aspeto que dedicamos a secção seguinte deste texto, no espírito da recomendação de Nation (2005, p. 5):

The first decision to make when teaching a word is to decide whether the word is worth spending time on or not. (...) In general, time should be spent on high frequency words or words that fill a language need that the learners have. 
CARECHO, Judite; Soares, Rute - Entrar na língua alemã pela porta do léxico: recursos para a aprendizagem autónoma de vocabulário

Para lá da tarefa: implicar os estudantes na aprendizagem de línguas estrangeiras no ensino superior. Porto: FLUP, 2019, pp. 95-115 DOI: https://doi.org/10.21747/9789898969217/paraa5

\section{4 - A problemática da escolha do vocabulário}

As listas de palavras do projeto ALEX foram criadas a partir das listas de palavras para estudo (Lernwortschatz) que o próprio manual usado na FLUC disponibiliza no final de cada lição, organizadas por temas ou, em alternativa, por categorias gramaticais, nomeadamente quando as palavras não estão ligadas ao tema da lição. O manual não disponibiliza nenhuma informação sobre os critérios de seleção de vocabulário, para além dos que se depreendem do facto de ser especialmente dirigido a quem pretenda frequentar o ensino superior, ou trabalhar, num país de língua alemã (Braun et al., 2016, p. 3).

A tarefa de adaptar as listas do manual ao projeto ALEX consistiu essencialmente em torná-las mais curtas e tão coerentes quanto possível, associando a cada palavra uma frase de contexto retirada da própria lição e uma tradução adequada da palavra nesse contexto. Para além de verificarmos a ocorrência efetiva das palavras da lista na lição em causa e de corrigirmos algumas incoerências nesse aspeto, houve, também, muitas vezes, necessidade de reorganizarmos as listas temáticas de modo a que a organização temática abrangesse o máximo de palavras e cada uma das listas tivesse um tamanho adequado à sua utilização nos exercícios gerados automaticamente pelas aplicações Leo e Quizlet.

A seleção do vocabulário a incluir e a excluir das listas do projeto ALEX, feita de acordo com os requisitos que acabámos de mencionar, revelou-se por vezes bastante complexa, em grande parte devido à incerteza sobre quais as palavras mais relevantes para um treino intensivo por parte dos alunos. Esta incerteza, aliada à ausência de explicitação dos critérios que presidiram à elaboração das listas de vocabulário para aprendizagem do próprio manual, suscitou a necessidade de compararmos o resultado do nosso trabalho com outras seleções de palavras elaboradas para fins semelhantes.

Um outro fator que reforçou essa necessidade foi a investigação existente sobre o vocabulário usado em manuais de ensino de Alemão, embora não incidindo especificamente sobre o manual usado na FLUC. Um estudo realizado em 2015 por Bubenhofer, Lange, Okamura e Scharloth analisou o vocabulário usado em nove manuais disponíveis no Japão (p. 95), comparando-o com uma lista de palavras organizada por frequência com base no corpus do projeto "Basic German", ${ }^{2}$ cujas

\footnotetext{
2 Este é o nome abreviado do projeto "Basic German Vocabulary for Foreign Language Learners: A data-driven Approach", também referido noutros textos com a designação alemã "Datengeleiteter Grund- und Aufbauwortschatz Deutsch" (cf. Lange, Okamura \& Scharloth, 2015).
} 
CARECHO, Judite; Soares, Rute - Entrar na língua alemã pela porta do léxico: recursos para a aprendizagem autónoma de vocabulário

Para lá da tarefa: implicar os estudantes na aprendizagem de línguas estrangeiras no ensino superior. Porto: FLUP, 2019, pp. 95-115 DOI: https://doi.org/10.21747/9789898969217/paraa5

características descrevemos brevemente, por serem determinantes para a fiabilidade dos resultados obtidos. Trata-se de um corpus alargado e constituído a partir de intervenções em fóruns na internet, por um lado, e textos de jornais e revistas, por outro. Os dois conjuntos de textos representam constelações comunicativas diferentes, a primeira de base oral com destinatários específicos, a segunda de base escrita e sem esses destinatários (Bubenhofer et al., 2015, p. 97). Acresce que a seleção e ordenação das palavras não segue um critério de frequência simples, mas recorre a critérios complementares, nomeadamente a estabilidade ao longo do tempo e em textos sobre diferentes temáticas, bem como a produtividade na formação de palavras (Bubenhofer et al., 2015, p. 97).

A lista de palavras assim constituída é usada numa análise do vocabulário dos manuais para a aprendizagem da língua alemã, da qual os autores concluem que o vocabulário selecionado é maioritariamente constituído por palavras de uso frequente e estável, recorrentes na formação de outras palavras, com uma distribuição relativamente uniforme de $40 \%$ de palavras com alta frequência/estabilidade/produtividade, $40 \%$ palavras de situadas no setor intermédio da mesma escala e $20 \%$ de palavras pouco frequentes/estáveis/produtivas. No entanto, ao contrário do que seria de esperar, este último grupo de palavras não se concentra sobretudo nas lições e nos níveis mais avançados de cada manual, estando distribuído ao longo das diferentes unidades didáticas (Bubenhofer et al., 2015, p. 101). Também inesperado na análise de manuais que se apresentam como seguindo uma orientação comunicativo-pragmática é o facto de o vocabulário da lista que é mais típico da constelação discursiva de base oral, com destinatários específicos, estar subrepresentado nos manuais, em contraponto com o vocabulário mais típico da constelação comunicativa de base escrita - ou seja, o facto de a linguagem de imprensa ser preponderante (cf. Bubenhofer et al., 2015, p. 102; e também o quadro apresentado em Lange, Okamura \& Scharloth, 2016, pp. 221-222). Embora o manual de Alemão adotado na FLUC não seja analisado no estudo que mencionámos, estas conclusões suscitam a necessidade de avaliarmos em que medida os ajustes que realizámos às listas de vocabulário contidas no manual contribuíram para a preservação das palavras nucleares e para a eliminação das palavras menos frequentes, estáveis e produtivas. 
CARECHO, Judite; Soares, Rute - Entrar na língua alemã pela porta do léxico: recursos para a aprendizagem autónoma de vocabulário

Para lá da tarefa: implicar os estudantes na aprendizagem de línguas estrangeiras no ensino superior. Porto: FLUP, 2019, pp. 95-115 DOI: https://doi.org/10.21747/9789898969217/paraa5

\section{1 - Possíveis termos de comparação}

Uma opção óbvia para comparar com as listas de palavras do projeto ALEX seria o vocabulário contido em Profile Deutsch, o trabalho de Glaboniat, Müller, Schmitz, Rusch e Wertenschlag (2002) que constitui uma aplicação prática à língua alemã dos princípios e níveis do Quadro Europeu Comum de Referência para as Línguas e se tornou uma referência clássica nesta área. São disponibilizados, para os diferentes níveis, não só vocabulário, agrupado por áreas temáticas, mas também estruturas gramaticais e exemplos de meios linguísticos para realizar diferentes intenções comunicativas, bem como referências a especificidades culturais, contemplando as três variedades nacionais da língua (alemã, austríaca e suíça). As decisões tomadas pela equipa de autores sobre os itens linguísticos a incluir apoiaram-se em outras listas e obras de referência já existentes (cf. Glaboniat et al., 2002, p. 11) - entre as quais Baldegger, Müller e Schneider (1980) -, bem como na sua própria experiência de ensino e aprendizagem (Glaboniat et al., 2002, p. 28).

As informações relativas ao Profile Deutsch não contêm, no entanto, referências detalhadas aos critérios que informaram essas decisões, como notam Möhring e Wallner (2013, p. 122). Estes são alguns dos autores que chamam a atenção para a falta de fundamentação empírica e de explicitação dos critérios usados para a seleção de vocabulário em trabalhos de orientação pragmático-comunicativa ${ }^{3}$ como o Profile Deutsch. Numa tentativa de comparar esses trabalhos com dados empíricos relativos à frequência de palavras na língua alemã, Möhring e Wallner verificam até que ponto o vocabulário do Profile Deutsch coincide com as palavras comuns a duas listas de frequência extraídas a partir de dois corpora da língua alemã (o DeReKo e o Herder/BYU). Os autores concluem que apenas 546 palavras atribuídas ao nível A1 no Profile Deutsch, isto é $61 \%$ do total desse nível, estão incluídas no vocabulário comum às listas de frequência dos dois corpora, considerando cerca de 5000 palavras de cada uma das listas (Möhring \& Wallner, 2013, p. 125). Se considerarmos como termo de comparação apenas as 1000 palavras mais frequentes em cada uma das listas, o número de palavras que se encontra também no nível A1 do Profile Deutsch desce para 294, isto é, claramente menos de metade das 778 contempladas no nível A1 (Möhring \& Wallner, 2013, p. 127). Segundo os autores, algumas destas divergências são

3 Cf. Bubenhofer et al. (2015, p. 86), que apontam a falta de fundamentação empírica consubstanciada na ausência de dados quantitativos relativamente ao uso linguístico típico em situações quotidianas, e ainda a falta de uma definição teórica dos conceitos de situação e quotidiano, bem como a não explicitação dos critérios de seleção do vocabulário. 
CARECHO, Judite; Soares, Rute - Entrar na língua alemã pela porta do léxico: recursos para a aprendizagem autónoma de vocabulário

Para lá da tarefa: implicar os estudantes na aprendizagem de línguas estrangeiras no ensino superior. Porto: FLUP, 2019, pp. 95-115 DOI: https://doi.org/10.21747/9789898969217/paraa5

compreensíveis e justificáveis por haver palavras como mieten, Gabel e Durst que, não sendo de alta frequência, satisfazem necessidades comunicativas elementares, o que se deverá às limitações dos corpora usados, que são tendencialmente escritos e compostos em boa parte por textos de imprensa, não abrangendo alguns temas importantes para as necessidades básicas do ser humano e o contexto da aula (Möhring \& Wallner, 2013, p. 128). Todavia, nem todas as divergências são explicáveis por critérios pragmáticos e comunicativos, pelo que os autores não deixam de considerar que este tipo de procedimentos empíricos é indispensável para fundamentar a seleção e atribuição de vocabulário aos diferentes níveis (Möhring \& Wallner, 2013, p. 130).

Uma segunda opção a considerar como termo de comparação com as listas de vocabulário do projeto ALEX são as listas da série Goethe-Zertifikat, até porque o manual de língua alemã usado na FLUC, o DaF Kompakt neu (Braun et al., 2016), se apresenta como recurso de preparação especificamente orientado para a prova Goethe/ÖSD-Zertifikat B1 (cf. Braun et al., 2016, p. 3). Quanto a critérios para a escolha do vocabulário das listas Goethe-Zertifikat, é indicada a relevância para a comunicação em situações do quotidiano nas esferas privada e pública, com ênfase nos domínios da educação e do trabalho, incluindo-se igualmente a terminologia necessária para a resolução das questões dos exames; refere-se ainda que é abrangida apenas a variedade alemã da língua (Perlmann-Balme, M. et al., (s.d.), p. 5; Perlmann-Balme, M. et al., 2016, p. 4). Como bases para o trabalho realizado, são indicadas outras listas de vocabulário pré-existentes, entre as quais se encontra o Profile Deutsch (PerlmannBalme, M. et al., (s.d.), p. 5). Os critérios de escolha de vocabulário mencionados nas listas Goethe-Zertifikat são, assim, de caráter comunicativo e geral, sem concretização de parâmetros e procedimentos, sendo ainda referido na lista do nível A1 que não foram considerados critérios de frequência relativos à comunicação entre falantes nativos da língua (Perlmann-Balme, M. et al., (s.d.), p. 5). Estas listas estão, portanto, sujeitas às mesmas críticas de que é alvo o Profile Deutsch, devido à falta de fundamentação empírica e de transparência no processo de seleção (cf., por exemplo, a posição de Möhring e Wallner (2013) referida acima e as críticas de Bubenhofer et al. (2015, p. 86) mencionadas na nota 3).

Sendo remota a possibilidade de sustentar empiricamente critérios de índole comunicativa para a seleção de vocabulário, a solução para evitar esse problema é o uso de listas de palavras elaboradas segundo a sua frequência. Precisamente com este objetivo, foi criado o projeto "Basic German" (www.basic-german.com, cf. nota 2). Dado que a seleção de vocabulário com base na sua frequência é sempre muito condicionada 
CARECHO, Judite; Soares, Rute - Entrar na língua alemã pela porta do léxico: recursos para a aprendizagem autónoma de vocabulário

Para lá da tarefa: implicar os estudantes na aprendizagem de línguas estrangeiras no ensino superior. Porto: FLUP, 2019, pp. 95-115 DOI: https://doi.org/10.21747/9789898969217/paraa5

pelo corpus utilizado, os autores deste projeto constituíram de raiz um corpus próprio, de grande dimensão e desenhado para garantir o equilíbrio relativamente às matrizes oral e escrita, como já foi referido na secção 4. Também na lista de palavras criada a partir deste corpus houve o cuidado de evitar a equiparação simplista entre alta frequência de um lexema e a sua importância no vocabulário para a aprendizagem, sendo o critério de frequência duplamente complementado: por um lado, pelo critério da estabilidade do uso da palavra ao longo dos anos e em textos sobre diferentes temáticas e, por outro lado, pelo critério da produtividade, isto é, da formação de compostos e derivados, da frequência destes e da ocorrência da palavra como segundo constituinte de um composto (cf. Lange, Okamura \& Scharloth, 2015, pp. 208-209). São estes critérios auxiliares que permitem, por exemplo, a decisão de colocar a palavra Frucht à frente de Futter na lista de frequência, já que o estatuto de ambas se assemelha ao nível da frequência simples no corpus, mas as palavras compostas e derivadas a partir da primeira estão presentes em textos com temáticas muito mais variadas (cf. Lange et al. 2015, pp. 211-213).

Uma lista de vocabulário criada desta forma criteriosa com base num corpus como 0 do "Basic German" apresenta-se, assim, como uma opção válida para a comparação com as listas de vocabulário do projeto ALEX, sobretudo se considerarmos posições como a de Nation e Chung (2009, pp. 543-545), que chamam a atenção para a necessidade de escolher estrategicamente as palavras mais frequentes para ensinar aos alunos (de Inglês Língua Estrangeira). Segundo os autores, este cuidado é essencial para acelerar a chegada dos alunos ao patamar de vocabulário necessário para leitura autónoma, que Nation indica ser o conhecimento de $98 \%$ das palavras do texto. Se há estudos que indicam que é necessário o aluno conhecer cerca de 8000 palavras para chegar a esses $98 \%$ na compreensão de textos de jornal (em inglês), outros mostram que, com as 2000 palavras mais frequentes, se consegue chegar a uma cobertura de $75 \%$, o que sublinha a importância de começar por ensinar as 2000 palavras mais frequentes. Tschirner (2006, p. 1285) apresenta dados paralelos aos de Nation e Chung para a língua alemã, estimando que a dimensão do vocabulário alemão necessário para atingir os $98 \%$ de cobertura em textos literários e de jornal é um pouco maior do que a do vocabulário inglês necessário para o mesmo fim, mas indicando que, nos dados por ele analisados, as 2000 palavras alemãs mais frequentes proporcionam uma cobertura de cerca de $90 \%$ do vocabulário em conversas, $80 \%$ em textos literários e $74 \%$ em textos de jornal. 
CARECHO, Judite; Soares, Rute - Entrar na língua alemã pela porta do léxico: recursos para a aprendizagem autónoma de vocabulário

Para lá da tarefa: implicar os estudantes na aprendizagem de línguas estrangeiras no ensino superior. Porto: FLUP, 2019, pp. 95-115 DOI: https://doi.org/10.21747/9789898969217/paraa5

Contudo, apesar das manifestas vantagens da seleção de vocabulário para a aprendizagem orientada por critérios de frequência, os próprios autores responsáveis pelo projeto "Basic German" acabam por concluir que esta abordagem está fortemente limitada pelo facto de se ater apenas à forma das palavras, não conseguindo distinguir diferentes significados ou usos do mesmo lexema em contextos distintos (cf. Lange et al., 2015, p. 218; Bubenhofer et al., 2015, p. 106). E o contexto não pode ser negligenciado, como mostra a comparação levada a cabo pelos autores entre listas de vocabulário básico criadas a partir de contextos comunicativos diferentes, da qual se conclui que "die Frequenz, Produktivität und Stabilität von Lexemen abhängig von den Kommunikationszwecken variiert" (Scharlot, Okamura \& Lange, 2016, p. 283). Os autores salientam que a lista das palavras mais frequentes, produtivas e estáveis não pode ser delimitada por meros critérios estatísticos tendo em mente a totalidade do léxico, ou seja, em abstrato e independentemente do objetivo. No que diz respeito à formação de vocabulários básicos de aprendizagem, a consequência dessa situação é que "Hinsichtlich der Wortschatzselektion ist für sie [=Grundwortschätze] eine Orientierung am Kommunikationszweck sinnvoll, ihr Umfang kann anhand didaktischer Kriterien begrenzt werden." (Scharlot et al., 2016, p. 283).

De facto, apesar do trabalho criterioso da equipa do projeto "Basic German", para que o corpus em que se baseia a sua lista de frequência tivesse uma composição equilibrada e, por isso, didaticamente adequada, o peso do texto jornalístico na sua conceção ainda é visível em detalhes como, por exemplo, a presença da palavra Angriff entre as mais frequentes (na posição 302). Por outro lado, a utilização direta desta lista na determinação do vocabulário a ensinar aos alunos enfrenta obstáculos práticos básicos como a ausência de etiquetagem relativamente aos níveis de proficiência linguística, a impossibilidade identificar significados diferentes para formas iguais e ainda a incoerência de lecionar segundo o critério de frequência conjuntos de palavras como os meses do ano, os dias da semana ou os números, quando só alguns dos seus membros estão marcados como sendo de alta frequência.

Assim, optámos por não usar a lista do projeto "Basic German" como base para a verificação das listas do projeto ALEX, mas apenas como recurso para deteção de falhas pontuais. A base escolhida para a comparação com as listas ALEX foram as listas Goethe-Zertifikat (cf. Perlmann-Balme, M. et al., (s.d.) e Perlmann-Balme, M. et al., (2016)), por serem listas de base comunicativa e didática mais recentes do que o Profile Deutsch, e por o manual DaF kompakt neu se apresentar como preparação orientada para o exame a que essas listas estão associadas. 
CARECHO, Judite; Soares, Rute - Entrar na língua alemã pela porta do léxico: recursos para a aprendizagem autónoma de vocabulário

Para lá da tarefa: implicar os estudantes na aprendizagem de línguas estrangeiras no ensino superior. Porto: FLUP, 2019, pp. 95-115 DOI: https://doi.org/10.21747/9789898969217/paraa5

\section{2 - Comparação entre as listas do projeto ALEX e as listas Goethe- Zertifikat}

Considerando o número total de palavras, verificamos que as listas do projeto ALEX para A1 e A2 são maiores do que as listas Goethe-Zertifikat para os mesmos níveis: a lista de A1 do ALEX totaliza 884 palavras, enquanto a lista Goethe-Zertifikat A1 contém 795 palavras, nas quais se incluem 23 palavras gramaticais como pronomes pessoais, que não se encontram no ALEX. No nível A2, a diferença é ainda maior, com a lista ALEX a contemplar 1027 palavras, enquanto a lista Goethe-Zertifikat $A 1$ contém apenas 722.

Uma das razões para a maior dimensão das listas ALEX pode residir no facto de termos optado por separar significados diferentes da mesma palavra em entradas diferentes na lista de vocabulário, acompanhadas de frases contextualizadoras e de traduções adequadas a esse contexto: por exemplo, besuchen tem uma entrada como 'frequentar a escola/assistir a aulas' e outra como 'visitar alguém'; spielen como 'jogar um jogo', 'tocar um instrumento musical' e 'representar um papel', sich vorstellen como 'apresentar-se' e como 'imaginar'. Pelo contrário, todos os casos deste tipo surgem nas listas Goethe-Zertifikat com uma única entrada e só na coluna dos exemplos podem ser encontradas frases para diferentes aceções. Sobretudo para alunos de iniciação, este não nos parece ser o procedimento pedagogicamente mais adequado. Há casos, como o de geben em es gibt e como verbo com o significado 'dar', em que aos diferentes significados corresponde até uma estrutura sintática diferente, pelo que consideramos vantajoso que estas diferenças sejam claramente apresentadas, correspondendo a itens separados na lista.

Um outro aspeto que pode ter contribuído para a maior dimensão das listas de vocabulário do ALEX em relação às listas Goethe-Zertifikat é um tratamento mais ou menos exaustivo de determinadas áreas temáticas como as peças de roupa, as partes do corpo ou as cores. Por exemplo, enquanto nas listas ALEX, e no manual que está na sua origem, o leque de palavras relacionadas com cores introduzido em A1 contempla 15 itens lexicais (blau, braun, gelb, grau, grün, lila, orange, rosa, rot, schwarz, weiß, beige, hell-, dunkel-, bunt), nas listas Goethe-Zertifikat são introduzidos 14 desses itens, mas apenas 8 (blau, braun, gelb, grau, grün, rot, schwarz, weiß) constam da lista de A1, figurando os restantes 6 (lila, orange, rosa, hell-, dunkel-, bunt) na lista de A2. 
CARECHO, Judite; Soares, Rute - Entrar na língua alemã pela porta do léxico: recursos para a aprendizagem autónoma de vocabulário

Para lá da tarefa: implicar os estudantes na aprendizagem de línguas estrangeiras no ensino superior. Porto: FLUP, 2019, pp. 95-115 DOI: https://doi.org/10.21747/9789898969217/paraa5

Mas, para além de compararmos a extensão das listas, é necessário verificarmos em que medida há coincidência entre as palavras que se encontram numas e noutras, 0 que pode ser observado na tabela seguinte:

\begin{tabular}{|c|c|c|}
\hline & Lista ALEX A1 & Lista ALEX A2 \\
\hline Número total de palavras & 884 & 1027 \\
\hline Palavras comuns & 413 & 131 \\
à lista do Goethe-Institut A1 (total 795) & $46,7 \%$ & $12,8 \%$ \\
\hline Palavras comuns & 155 & 189 \\
à lista do Goethe-Institut A2 & $17,5 \%$ & $18,4 \%$ \\
(total 722, excluindo os repetidos de A1) & 316 & 707 \\
\hline $\begin{array}{c}\text { Palavras não comuns } \\
\text { às listas do Goethe-Institut A1 e A2 }\end{array}$ & $35,8 \%$ & $68,8 \%$ \\
\hline
\end{tabular}

Figura 4. Coincidência de palavras nas listas ALEX e Goethe-Zertifikat

Nas listas de nível A1 coincidem menos de metade das palavras, uma diferença que é mitigada por haver $17,5 \%$ de palavras que constam da lista Goethe-Zertifikat A2. No entanto, mais de $30 \%$ das palavras do ALEX A1 não se encontra nas listas GoetheZertifikat, nem A1 nem A2. No nível A2 o cenário é ainda mais divergente: as palavras comuns às listas ALEX A2 e Goethe-Zertifikat A2 não chegam a 20\%, e apenas pouco mais de $12 \%$ das palavras da lista ALEX A1 está na lista Goethe-Zertifikat A2. Ou seja, quase $70 \%$ das palavras da lista ALEX A2 não está em nenhuma das listas GoetheZertifikat analisadas.

Considerando as listas e o contexto no qual foi criado o projeto ALEX, são plausíveis várias razões, de natureza diversa, para as discrepâncias assinaladas na tabela.

Uma dessas razões prende-se com o tratamento dos mesmos temas em níveis diferentes: por exemplo, o léxico relativo ao corpo humano surge em A1 nas listas Goethe-Zertifikat e em A2 nas listas ALEX, sucedendo exatamente o oposto com os temas vestuário e disciplinas/áreas do saber.

No caso dos temas desporto e ensino superior, não se trata de se situarem em níveis diferentes, mas sim de serem explorados no manual que serve de base às listas do ALEX e de se encontrarem sub-representados nas listas Goethe-Zertifikat. Sobretudo o tema ensino superior tem claramente um interesse imediato para os alunos a quem se destina o projeto ALEX, pelo que nos parece justificado incluir termos como Klausur, ein 
CARECHO, Judite; Soares, Rute - Entrar na língua alemã pela porta do léxico: recursos para a aprendizagem autónoma de vocabulário

Para lá da tarefa: implicar os estudantes na aprendizagem de línguas estrangeiras no ensino superior. Porto: FLUP, 2019, pp. 95-115 DOI: https://doi.org/10.21747/9789898969217/paraa5

Referat halten, Studentenwohnheim e Hausmeister, mesmo que isso implique uma maior extensão das listas.

Um outro domínio que as listas ALEX abrangem é o das aulas e da explicação metalinguística, enquanto as listas do Goethe-Zertifikat são mais limitadas nessa área temática, não contendo, por exemplo, palavras como Übung, Verb, Vergangenheit, Zukunft, Regel. Consideramos que também este domínio justifica um alargamento da lista, pois, na sua grande maioria, o público das turmas de licenciatura não pretende simplesmente ter um domínio utilitário da língua alemã, mas é antes constituído por potenciais futuros profissionais das línguas, que devem conhecer o vocabulário básico para descrever o seu funcionamento.

Uma outra razão para as discrepâncias e para a maior dimensão das listas ALEX é o facto de estas incluírem um certo número de palavras compostas e derivados sufixais (por exemplo, com -ung, -er e -in), contrariamente à estratégia das listas GoetheZertifikat, que exclui expressamente a generalidade desses casos (Perlmann-Balme, M. et al., (s.d.), p. 5, Perlmann-Balme, M. et al., (2016), p. 4). Também aqui nos parece justificar-se uma estratégia diferente no caso dos nossos alunos, que, estando a iniciarse na língua, têm a princípio alguma dificuldade em apreender o significado de palavras compostas e derivadas. O mesmo acontece com algumas combinatórias de palavras contidas nas listas ALEX - como é o caso de die Autobahn nehmen, ein Referat/eine Präsentation halten, Geld entnehmen, Geld einzahlen -, que constituem sempre dificuldades para os alunos, nomeadamente no uso produtivo do vocabulário.

Sobretudo em A2, a inclusão de termos que vão além das listas Goethe-Zertifikat teve também origem na própria exigência dos exercícios do manual. Estes são, por vezes, muito específicos e têm frequentemente mais do que uma pergunta que exige o conhecimento de determinadas palavras que de outra forma poderiam não ser incluídas (alguns exemplos são Beipackzettel, Buchhaltung, Dach, Decke, Diät, Dieb, Dom, blitzen, donnern).

Há ainda outras discrepâncias entre as listas analisadas que se devem à relevância de determinadas palavras para alunos portugueses, ou por serem falsos amigos (como é o caso de komisch, Limonade, Marmelade, Saal, studieren, Student, ambulant), ou por estarem relacionadas com especificidades culturais do ponto de vista de um aprendente português. Por exemplo, para um português num país de língua alemã, pode ser muito útil saber que Espresso é a palavra necessária para obter o mesmo que obtém em Portugal quando pede um café, que, ao pedir uma garrafa de água, precisa de especificar que a quer sem gás usando a expressão ohne Kohlensäure, que wandern 
CARECHO, Judite; Soares, Rute - Entrar na língua alemã pela porta do léxico: recursos para a aprendizagem autónoma de vocabulário

Para lá da tarefa: implicar os estudantes na aprendizagem de línguas estrangeiras no ensino superior. Porto: FLUP, 2019, pp. 95-115 DOI: https://doi.org/10.21747/9789898969217/paraa5

corresponde a fazer uma caminhada e não a dar um simples passeio, ou que o verbo jobben descreve a situação extremamente frequente de os estudantes ganharem algum dinheiro com trabalhos ocasionais. Pelo contrário, a proximidade entre certas palavras alemãs que constam das listas Goethe-Zertifikat - como Text, Baby, automatisch, Banane, Café, Chef e Film - e as correspondentes portuguesas (ou inglesas) justifica plenamente a sua ausência das listas ALEX (ou, em certos casos, a sua inclusão num subgrupo de lexemas "zum Hören/para ouvir", com os quais pretendemos chamar a atenção para diferenças, não no significado, mas na pronúncia e na grafia).

Por fim, há igualmente algumas omissões que constituem falhas da seleção de palavras para as listas ALEX, ou provenientes do próprio manual, ou da adaptação das listas ao projeto. É o caso de palavras como: Stunde, Alter, Antwort, antworten, Frage, Aufgabe, Blatt, gestern, bitte, danke, Entschuldigung. Por outro lado, a comparação das listas revela que a seleção vocabular do Goethe-Zertifikat também não está isenta de falhas: por exemplo, é estranho que a palavra etwas surja apenas no nível A2, quando está presente em tantas frases bastante simples que contextualizam palavras do nível A1. Um outro exemplo são as palavras Kind e Mann, que se encontram na lista GoetheZertifikat $A 1$ associadas a exemplos que correspondem apenas a um dos seus sentidos, nomeadamente o de membro da família (Wie viele Kinder haben Sie? Mein Mann arbeitet bei der Polizei). Pelo menos para alunos portugueses, em cuja língua materna há palavras diferentes para os dois significados de Mann e Kind, esta apresentação das palavras omite totalmente o seu significado de base como 'criança' e 'homem', ao contrário do que acontece na entrada da palavra Frau, que é acompanhada de exemplos das diversas aceções.

\section{5 - Conclusões e alterações a implementar no projeto}

Das reflexões expostas nas secções 3 e 4 decorrem algumas propostas de alteração do projeto ALEX no sentido de aperfeiçoar os aspetos menos conseguidos e aumentar a eficácia dos recursos.

Relativamente às listas de vocabulário, em próximas edições do projeto faremos uma revisão das listas com base na comparação com as listas Goethe-Zertifikat, bem como no recurso pontual à lista "Basic German", colmatando lacunas detetadas através desta comparação e eliminando palavras que a comparação revele serem menos úteis. Um outro aspeto a implementar será a sinalização das palavras essenciais, de modo a permitir que os alunos trabalhem de forma faseada, começando com um conjunto mais 
CARECHO, Judite; Soares, Rute - Entrar na língua alemã pela porta do léxico: recursos para a aprendizagem autónoma de vocabulário

Para lá da tarefa: implicar os estudantes na aprendizagem de línguas estrangeiras no ensino superior. Porto: FLUP, 2019, pp. 95-115 DOI: https://doi.org/10.21747/9789898969217/paraa5

pequeno de palavras, se assim o desejarem. Sobretudo no nível A2, é também de repensar a estratégia a seguir com as palavras compostas, com as quais os alunos já saberão lidar melhor, assim como a inclusão de palavras necessárias aos exercícios do manual, mas que não sejam consideradas frequentes ou de clara utilidade.

No que respeita ao trabalho de organização do projeto, a opção será fazer uma segunda edição limitada apenas ao nível $\mathrm{A} 1$, dados os constrangimentos na velocidade a que conseguimos produzir e atualizar os recursos. Os exercícios a criar devem ser de dimensão limitada, para uma maior flexibilidade, e maximizar as potencialidades do telemóvel, dada a preferência dos alunos por este dispositivo, bem como ser testados sistematicamente antes da sua disponibilização.

Serão realizadas, tão cedo quanto possível, sessões presenciais de apresentação do projeto que incluam treino prático alargado, de modo a evitar dificuldades posteriores no trabalho autónomo. Estas sessões devem incluir também esclarecimentos sobre a utilidade destes exercícios na aprendizagem de vocabulário e sobre a importância do vocabulário na aprendizagem da língua, atendendo sobretudo ao facto de os alunos virem genericamente de um percurso de aprendizagem tradicional muito dependente do professor, sem o hábito de pensarem eles próprios na sua aprendizagem, recorrendo ao trabalho autónomo com ferramentas tecnológicas para este efeito.

Por último, pretendemos também fazer um esforço de aproximação entre o projeto e as atividades das aulas, de modo a tirar partido dessa fonte de motivação para os alunos e a tentar responder à reflexão final de Kukulska-Hulme (2009, p. 164): "the challenge is to develop designs that clearly identify what is best learnt in the classroom, what should be learnt outside, and the ways in which connections between these settings will be made."

Futuramente, estaremos em condições de avaliar o impacto destas propostas de alteração. À data de redação deste texto, o que podemos afirmar é que a segunda edição do projeto ALEX conta com uma participação mais robusta e regular por parte dos alunos.

\section{Referências bibliográficas}

Baldegger, M., Müller, M. \& Schneider, G. (1980). Kontaktschwelle Deutsch als Fremdsprache. München: Langenscheidt.

Bubenhofer, N., Lange, W., Okamura, S. \& Scharloth, J. (2015). Wortschätze in Lehrwerken für Deutsch als Fremdsprache: Möglichkeiten und Grenzen 
CARECHO, Judite; Soares, Rute - Entrar na língua alemã pela porta do léxico: recursos para a aprendizagem autónoma de vocabulário

Para lá da tarefa: implicar os estudantes na aprendizagem de línguas estrangeiras no ensino superior. Porto: FLUP, 2019, pp. 95-115 DOI: https://doi.org/10.21747/9789898969217/paraa5

frequenzorientierter Ansätze. In J. Kiesendahl \& C. Ott (Eds.), Linguistik und Schulbuchforschung: Gegenstände, Methoden, Perspektiven (pp. 85-108). Göttingen: V\&R unipress.

Braun, B., Doubek, M., Fügert, N., Kotas, O., Langermann, M. M., Curcio, M. N., ..., Walter, M. (2016). DaF kompakt neu A1-B1: Kursbuch mit MP3-CD. Stuttgart: Klett.

Carecho, J., Soares, R. \& Fernandes, A. (2018). ALEX: palavras em movimento na aprendizagem de Alemão. In A. A. Carvalho, J. P. Pons, C. G. Marques, S. Cruz, A. Moura, I. L. Santos \& D. Guimarães (Eds.), Atas do $4^{\circ}$ Encontro sobre Jogos e Mobile Learning (pp. 78-84). Coimbra: CEIS20. http://hdl.handle.net/10316/48542

Glaboniat, M., Müller, M., Schmitz, H., Rusch, P. \& Wertenschlag, L. (2002). Profile Deutsch: Gemeinsamer europäischer Referenzrahmen. Berlin: Langenscheidt.

Hubbard, P. (2013). Making a Case for Learner Training in Technology Enhanced Language Learning Environments. CALICO Journal, 30(2), 163-178. doi:10.11139/cj.30.2.163-178

Kukulska-Hulme, A. (2009). Will mobile learning change language learning? ReCALL, 21(2), 157-165.

Lange, W., Okamura, S. \& Scharloth, J. (2015). Grundwortschatz Deutsch als Fremdsprache: Ein datengeleiteter Ansatz. In J. Kilian \& J. Eckhoff (Eds.), Deutscher Wortschatz - beschreiben, lernen, lehren. Beiträge zur Wortschatzarbeit in Wissenschaft, Sprachunterricht, Gesellschaft (pp. 203-219). Frankfurt am Main u.a.: Peter Lang.

Lange, W., Okamura, S. \& Scharloth, J. (2016). Datengeleiteter Grundwortschatz Deutsch: Kriterien für die Lemmaselektion. In P. Colliander, H. Drumbl, D. Höhmann, S. Ivanenko, D. Knorr \& S. Moraldo (Eds.), Linguistische Grundlagen für den Sprachunterricht (2 ${ }^{\underline{a}}$ ed.; pp. 217-226). Bozen: Bolzano University Press.

Laufer, B. \& Nation, I.S.P. (2012). Vocabulary. In S. M. Gass \& A. Mackey (Eds.), The Routledge Handbook of Second Language Acquisition (pp. 163-176). New York: Routledge.

Ma, Q. (2017). Technologies for Teaching and Learning L2 Vocabulary. In C. A. Chapelle \& S. Sauro (Eds.), The Handbook of Technology and Second Language Teaching and Learning (pp. 45-61). Oxford: Wiley Blackwell.

Möhring, J. \& Wallner, F. (2013). Wortschatzlisten auf dem Prüfstand. Aussiger Beiträge, 7, 119-133.

Nation, I.S.P. (2005). Teaching Vocabulary. Asian EFL Journal, 7(3), 47-54. 
CARECHO, Judite; Soares, Rute - Entrar na língua alemã pela porta do léxico: recursos para a aprendizagem autónoma de vocabulário

Para lá da tarefa: implicar os estudantes na aprendizagem de línguas estrangeiras no ensino superior. Porto: FLUP, 2019, pp. 95-115 DOI: https://doi.org/10.21747/9789898969217/paraa5

Nation, P. \& Chung, T. (2009). Teaching and Testing Vocabulary. In M. C. Long \& C. J. Doughty (Eds.), The Handbook of Language Teaching (pp. 536-559). London: WileyBlackwell.

Perlmann-Balme, M. et al. (s.d.). Goethe-Zertifikat A1. Start Deutsch 1: Wortliste. München: Goethe-Institut.

https://www.goethe.de/pro/relaunch/prf/de/A1_SD1_Wortliste_02.pdf Acesso em 3.9.2018.

Perlmann-Balme, M. et al. (2016). Goethe-Zertifikat A2: Wortliste. München: GoetheInstitut.

https://www.goethe.de/pro/relaunch/prf/de/Goethe-Zertifikat_A2_Wortliste.pdf Acesso em 3.9.2018.

Scharloth, J., Okamura, S. \& Lange, W. (2016). Gibt es einen Kernwortschatz? Datengeleitete Perspektiven auf die Erstellung von Grundwortschätzen für Deutsch als Fremdsprache. In S. Brunetti, J. Klingebeil-Schieke, C. M. Pedron, M-C. Piotrowski, A. Ruggieri, R. Schreiber (Eds.), Versprachlichung von Welt. II mondo in parole. Festschrift zum 60. Geburtstag von Maria Lieber (pp. 273-284). Tübingen: Stauffenburg.

Soares, R., Carecho, J. \& Fernandes, A. (no prelo). Aprender vocabulário fora das paredes da sala de aula. In R. García-Ruiz, A. P. Escoda \& M. D. G. Franco (Eds.), Dispositivos móviles en el aula: docentes y estudiantes prosumidores en la era digital. Sevilla: Egregius Ediciones.

Stockwell, G. (2016). Mobile language learning. In F. Farr \& L. Murray (Eds.), The Routledge Handbook of Language Learning and Technology [e-book] (pp. 959-997). New York: Routledge.

Tschirner, E. (2006). Häufigkeitsverteilungen im Deutschen und ihr Einfluss auf den Erwerb des Deutschen als Fremdsprache. In E. Corina, C. Marello, C. Onesti (Eds.), Atti del XII Congresso Internationale di Lessicografia (pp. 1277-1288). Alessandria: Edizioni dell' Orso.

Zhang, Y. (A.) (2015). Characteristics of Mobile Teaching and Learning. In Y. (A.) Zhang (Ed.), Handbook of Mobile Teaching and Learning (pp. 11-28). Berlin/Heidelberg:

Springer. 